ARAŞTIRMA MAKALESI

\title{
4-36 Ay Arası Bebeklerin Diş Çıkarma Sürecinde Yaşadıkları Sorunlar ve Annelerin Yaptıkları Uygulamalar
}

\author{
Zeynep ERKUT ${ }^{1}$, (D) Selmin KÖSE², (iD) Fatma DUMANDA $\breve{G}^{3}$
}

'Dr. Öğr. Üyesi, Biruni Üniversitesi Sağlık Bilimleri Fakültesi, Hemşirelik (İngilizce) Bölümü, İstanbul

${ }^{2}$ Dr. Öğr. Üyesi, Biruni Üniversitesi Sağlık Bilimleri Fakültesi, Hemşirelik Bölümü, İstanbul

${ }^{3}$ Uzm. Hemşire Kumkapı Aile Sağlığı Merkezi, İstanbul

Öz

Giriş: Diş çıkarma, bütün bebeklerin yaşadığı fizyolojik bir süreçtir. Bu süreçte birçok lokal ve sistemik semptom görülmektedir. Amaç: Araştırma, 4-36 ay arası bebeklerin diş çıkarma sürecinde yaşadıkları sorunları ve annelerin sorunlarla baş etmek için yaptıkları uygulamaları belirlemek amacıyla gerçekleştirildi. Yöntem: Tanımlayıcı ve kesitsel tipteki araştırma 30 Ekim 2020-10 Ocak 2021 tarihleri arasında İstanbul ilinde bulunan bir Aile Sağlığı Merkezi’nde yürütüldü. Araştırmanın örneklemini bu merkeze kayıtlı 145 bebeğin annesi oluşturdu. Veriler araştırmacılar tarafından literatür taraması sonucu hazırlanan 'Anket Formu' aracılığıyla toplandı. Verilerin analizi SPSS 22.0 programında yapıldı. Bulgular: Bebeklerin ortalama diş çıkarma zamanının $7.55 \pm 2.24(\min =4$; $\max =18)$ ay olduğu bulundu. Bebeklerin çıkan ilk dişinin, sağ alt ön kesici diş (\%49.0) olduğu, bunu sol alt ön kesici dişin (\%32.4) izlediği saptandı. Diş çıkarma sırasında bebeklerin çoğunun (\%95.9) en az bir sorun yaşadığı ve en fazla görülen sorunların huzursuzluk (\%76.6), diş etlerinde kızarıklık ve kaşıntı (\%64.8), 1sırma ve çiğnemede artış (\%55.2), salyada artış (\%52.4), uykusuzluk (\%49.7) ve ateş (\%48.3) olduğu saptandı. Bu sorunlara yönelik annelerin en fazla yaptıkları uygulamaların; çiğnemesi için yiyecek verme (\%71.0), diş kaşıma halkası verme (\%60.0), diş jeli sürme (\%43.4), hekimin önerdiği ağrı kesici ilaç verme (\%35.9), diş etine masaj yapma (\%34.5) olduğu bulundu. Sonuç: Annelerin tamamına yakını diş çıkma sürecinde bebeklerinin sorun yaşadığını belirtmektedir. Hemşireler tarafından bu sorunlara yönelik uygun yöntemlerin seçilmesi konusunda ebeveynlere bilgi verilmelidir.

Anahtar Sözcükler: Diş Çıkarma, Bebek, Anne, Hemşire.

\section{Abstract}

Problems Experienced by Babies Between 4-36 Months

During Teething Process and the Practices Made by Mothers

Background: Teething is a physiological process that all babies experience. Many local and systemic symptoms are seen in this process. Objective: The study was carried out to determine the problems experienced by babies between 4-36 months during the teething process and the practices of mothers to cope with the problems. Methods: The descriptive and cross-sectional study was conducted between 30 October 2020-10 January 2021 in a Family Health Center in Istanbul. The sample of the study was the mothers of 145 babies registered in this center. The data were collected through the 'Questionnaire Form' prepared by the researchers as a result of the literature review. Data analysis was done in SPSS 22.0 program. Results: It was found that the mean eruption time of babies was $7.55 \pm 2.24(\min =4$; $\max =18)$ months. It was determined that the first tooth of the babies erupted was the right lower anterior incisor $(49.0 \%)$, followed by the left lower anterior incisor (32.4\%). It was found that most babies (95.9\%) had at least one problem during teething and the most common problems were restlessness (76.6\%), redness and itching of the gums (64.8\%), increased bitting and chewing (55.2\%), increased salivation (52.4\%), sleeplessness (49.7\%) and fever (48.3\%). It was found that the most common practices of mothers for these problems were giving food to chew (71.0\%), giving teething ring (60.0\%), applying dental gel (43.4\%), giving pain medication recommended by the physician (35.9\%), and massaging the gums (34.5\%). Conclusion: Almost all mothers stated that their babies have problems during the teething process. Parents should be informed about the selection of appropriate methods for these problems by the nurses.

Key Words: Tooth Eruption, Infant, Mother, Nurse.

Geliş Tarihi / Received: 26.01.2021 Kabul Tarihi / Accepted: 18.06.2021

Correspondence Author: Zeynep ERKUT, Dr. Öğr. Üyesi, Biruni Üniversitesi Sağlık Bilimleri Fakültesi, Hemşirelik (İngilizce) Bölümü, İstanbul, Türkiye. Telefon: +90 4448 276, E-posta: zerkut@biruni.edu.tr

Cite This Article: Erkut Z, Köse S, Dumandağ F. 4-36 Ay Arası Bebeklerin Diş Çıkarma Sürecinde Yaşadıkları Sorunlar ve Annelerin Yaptıkları Uygulamalar. Dokuz Eylül Üniversitesi Hemşirelik Fakültesi Elektronik Dergisi. 2021; 14(3): 232- 239 
C ağzında ilk süt dişinin çıkması çocuğun yaşamında bir dönüm noktası olarak kabul edilmektedir (1). Toplam 20 adet olan süt dişleri doğumdan 4-10 ay sonra çıkmaya başlar ve 30-36. aylar arasında tamamlanır $(2,3)$. Dişler genellikle önden arkaya, aşağıdan yukarıya doğru çıkmaktadır (4). Diş gelişimi bireysel farklılıklar gösterir ve bu gelişim birçok faktörden etkilenir. Bu faktörler arasında genetik özellikler, prenatal ve maternal faktörler, hormonlar, sistemik hastalıklar, cinsiyet, beslenme, prematürite, sosyoekonomik durum, iklim ve pasif sigara içiciliği gibi özellikler bulunmaktadır $(3,5,6,7)$.

Diş çıkarma, bütün çocuklar için normal gelişimsel bir süreçtir (7). Ancak 5000 yıldan fazla süredir, birçok kültür tarafindan bu doğal süreç, bebeklerde ve küçük çocuklarda çeşitli sağlık sorunlarının nedeni olarak görülmüştür (8). Çünkü diş çıkarma sürecine eşlik eden birçok lokal ve sistemik semptom vardır. Bu semptomlar arasında ateş, huzursuzluk, uykusuzluk, salyada artış, diş etlerinde kızarıklık ve kaşıntı, 1sırma ve çiğnemede artış, iştahta azalma, emme isteğinde artış, ishal, kabızlık, kulakta kaşıntı, burun akıntısı, burun tıkanıklığı, öksürük, bez bölgesinde kızarıklık, pişik, döküntü, yüzde veya vücutta kızarıklık bulunmaktadır (8-14). Diğer taraftan bu belirtilerin diş çıkarmaya özgü olduğunu gösteren hiçbir bilimsel kanıt yoktur (12).

Diş çıkarma süreci aile açısından oldukça zor geçen bir dönemdir ve çoğu ebeveyn için endişe kaynağıdır (3). Ebeveynler diş çıkarma sürecinde çocuklarının yaşadıkları problemlerin dişlerden mi yoksa daha ciddi bir sağlık probleminden mi kaynaklandığına yönelik yoğun endişe yaşamaktadır (8). Bu endişeleri nedeniyle genellikle farmakolojik veya farmakolojik olmayan birçok yöntem kullanmaktadır (12). Literatürde ebeveynlerin çocuklarının diş çıkarma sürecinde yaşadıkları sorunlarla baş etmek için diş jeli sürme, diş kaşıma halkası kullanma, diş etine masaj yapma, ağrı kesici verme, antibiyotik verme, doğal bitkisel ürün verme, çiğnemesi için yiyecek verme, emzirme sıklığını artırma, emzik verme, amber (kehribar) taşlı kolye veya bileklik takma gibi çeşitli yöntemleri kullandıkları belirtilmektedir $(3,4,8,10-12,15)$. Çocuk sağlığı alanında çalışan hemşireler aile açısından oldukça zorlu geçen diş çıkarma sürecinde ebeveynlere rehberlik etmeli, kullandıkları farmakolojik veya farmakolojik olmayan yöntemleri belirleyerek diş çıkarma sürecinde çocukların yaşadıkları problemleri azaltmaya yönelik uygun girişimler hakkında ebeveynleri bilgilendirmelidir $(4,7)$.

\section{Amaç}

Bu araştırmanın amacı 4-36 ay arası bebeklerin diş çıkarma sürecinde yaşadıkları sorunları ve annelerin bu sorunlarla baş etmek için yaptıkları uygulamaları belirlemektir.

\section{Araştırma Soruları}

- 4-36 arası bebeklerin diş çıkarma sürecinde yaşadıkları sorunlar nelerdir?

- Anneler diş çıkarma sürecinde çocuklarının yaşadıkları sorunlara yönelik hangi uygulamaları kullanmaktadır?

\section{Araștırmanın Tipi}

Yöntem

Nicel olarak tasarlanan bu araştırma tanımlayıcı ve kesitsel tiptedir.

\section{Araştırmanın Yapıldı̆̆ Yer ve Tarihi}

Bu araştırma İstanbul ilinde bulunan bir Aile Sağlı̆̆ı Merkezi’nde 30 Ekim 2020-10 Ocak 2021 tarihleri arasında yürütüldü.

\section{Araşturmanın Evreni ve Örneklemi}

Araştırmanın evrenini, araştırmanın yürütüldüğü Aile Sağlığı Merkezi’ne kayıtlı olan 4-36 ay arası 354 bebek ve anneleri oluşturdu. Araştırmaya dahil edilme kriterleri; annenin araştırmaya katılmaya gönüllü olması, bebeğin 4-36 ay arasında olması, bebeğin en az bir dişinin çıkması, annenin soruları anlayacak ve yanıt verecek düzeyde Türkçe bilmesi ve annenin soruları yanıtlayacak zihinsel yeterliliğe sahip olmasıdır. Araştırmaya dahil edilecek katılımcı sayısının belirlenmesinde evreni bilinen örneklem yöntemi kullanıldı. Örneklem sayıs1 \%95 güven aralığında, p (incelenen olayın gerçekleşme olasılığı) $=0.8$ olarak kabul edilerek $\pm \% 5$ örnekleme hatası için 145 bebek ve annesi olarak hesaplandı. Örneklem seçimi basit rastgele örnekleme yöntemi ile yapıldı. Bu doğrultuda araştırmaya dahil edilecek bebekler kura çekme yöntemiyle belirlendi. Araştırma 145 bebek ve annesi ile gerçekleștirildi.

\section{Veri Toplama Araçlart}

Araştırma verileri araştırmacılar tarafından literatür taraması $(1-4,10)$ sonucu hazırlanan "Anket Formu" aracılığıyla toplandı. Anket formu bebeğin ve ailenin sosyo-demografik özelliklerini, bebeklerin diş çıkarma sürecinde yaşadıkları sorunları ve annelerin bu sorunlara yönelik yaptıkları uygulamaları sorgulayan 22 çoktan seçmeli ve 15 açık uçlu olmak üzere toplam 37 sorudan oluşmaktadır.

\section{Verilerin Toplanmast}

Araştırma verileri, araştırmanın yapıldığ 1 Aile Sağlığı Merkezi’nde çalışan araştırmacılardan biri tarafından toplandı. Haftanın beş günü (pazartesi-cuma günleri arası) 08:30-16:30 saatleri arasında araştırmanın yapıldığı merkeze gelen ve araştırmaya dahil edilme kriterlerine uyan annelere araştırma hakkında bilgi verilerek, yüz yüze görüşme tekniği ile toplandı. Anketin doldurulması yaklaşık 10-15 dakika sürdü.

\section{Verilerin Değerlendirilmesi}

Araştırmadan elde edilen veriler bilgisayar ortamında, IBM SPSS Statistics 22 (IBM SPSS, Türkiye) programı ile değerlendirildi. Değişkenlerin normal dağılıma uygunluğu Kolmogorov-Smirnov testi ile değerlendirildi. Tanımlayıcı istatistikler olarak sayı, yüzde, ortalama ve standart sapmadan yararlanıldı. Normal dağılım gösteren verilerin iki grup arası karşılaştırması için Student $\mathrm{t}$ testi kullanıld. İstatistiksel anlamlılık $\mathrm{p}<.05$ olarak kabul edildi.

\section{Araştırmanın Etik Yönü}

Araştırmanın yürütülebilmesi için etik kurul onayı (Tarih/Sayı:30.10.2020/2020-44-14) ve araştırmanın yapıldığı Aile Sağlığı Merkezi'nden kurum izni alındı. Araştırmaya başlamadan önce, araştırmacı tarafından annelere bireysel bilgilerinin korunacağı belirtildi ve gönüllük ilkesi doğrultusunda sözel ve yazılı onamları alındı. Ayrıca makalede, araştırma ve yayın etiğine uyuldu. 


\section{Bulgular}

Araştırmaya alınan bebeklerin gestasyon hafta ortalamasının 38.49 \pm 1.42 hafta, doğum ağırlığı ortalamasının $3195.65 \pm 501.78$ gram, doğum boyu ortalamasının $49.82 \pm 3.16$ cm olduğu bulundu. Bebeklerin \%51.0'inin erkek olduğu, bebeklerin \%57.9'unun sezeryan doğum ile dünyaya geldiği saptandı. Annelerin yaş ortalamasının $29.19 \pm 5.42$ y1l, \%36.6'sının ilköğretim mezunu olduğu ve \%78.6'sının çalışmadığı belirlendi. Babaların yaş ortalamasının 33.08 \pm 5.56 yı1, \%33.1'inin ilköğretim, \%33.1'inin üniversite mezunu olduğu ve \%86.2'sinin çalıştığı bulundu. Annelerin \%15.9'unun, babaların \%49.7'sinin sigara içtiği, ailelerin \%82.1'inin çekirdek aile olduğu, \%69.2'sinin 1 ya da 2 çocuğu olduğu ve \%47.6'sının gelirinin giderinden az olduğu saptandı (Tablo 1).

Tablo 1. Katılımcıların Tanıtıcı Özelliklerinin Dağılımı $(N=145)$

\begin{tabular}{|c|c|c|c|}
\hline Tanıtıcı Özellikler & & \multicolumn{2}{|c|}{ Ortalama \pm SS } \\
\hline \multicolumn{2}{|l|}{ Gestasyon haftası } & \multicolumn{2}{|c|}{$38.49 \pm 1.42$} \\
\hline \multicolumn{2}{|l|}{ Doğum ağırlığı (gram) } & \multicolumn{2}{|c|}{$3195.65 \pm 501.78$} \\
\hline \multicolumn{2}{|l|}{ Doğum boyu (cm) } & \multicolumn{2}{|c|}{$49.82 \pm 3.16$} \\
\hline Anne yaşı & & \multicolumn{2}{|c|}{$29.19 \pm 5.42$} \\
\hline \multirow[t]{2}{*}{ Baba yaşı } & & \multicolumn{2}{|c|}{$33.08 \pm 5.56$} \\
\hline & & $\mathbf{n}$ & $\%$ \\
\hline \multirow{2}{*}{ Cinsiyet } & $\mathrm{K}_{1 \mathrm{z}}$ & 71 & 49.0 \\
\hline & Erkek & 74 & 51.0 \\
\hline \multirow{2}{*}{ Doğum şekli } & Normal & 61 & 42.1 \\
\hline & Sezeryan & 84 & 57.9 \\
\hline \multirow{2}{*}{ Anne çalışma durumu } & Evet & 31 & 21.4 \\
\hline & Hayır & 114 & 78.6 \\
\hline \multirow{5}{*}{ Anne eğitim durumu } & Okur yazar değil & 15 & 10.3 \\
\hline & Okur yazar & 6 & 4.1 \\
\hline & İlköğretim & 53 & 36.6 \\
\hline & Lise & 27 & 18.6 \\
\hline & Üniversite & 44 & 30.3 \\
\hline \multirow{2}{*}{ Baba çalışma durumu } & Evet & 125 & 86.2 \\
\hline & Hayır & 20 & 13.8 \\
\hline \multirow{5}{*}{ Baba eğitim durumu } & Okur yazar değil & 16 & 11.0 \\
\hline & Okur yazar & 4 & 2.8 \\
\hline & İlköğretim & 48 & 33.1 \\
\hline & Lise & 29 & 20.0 \\
\hline & Üniversite & 48 & 33.1 \\
\hline \multirow{2}{*}{ Anne sigara içme durumu } & Evet & 23 & 15.9 \\
\hline & Hayır & 122 & 84.1 \\
\hline \multirow{2}{*}{ Baba sigara içme durumu } & Evet & 72 & 49.7 \\
\hline & Hayır & 73 & 50.3 \\
\hline \multirow{2}{*}{ Aile Tipi } & Çekirdek aile & 119 & 82.1 \\
\hline & Geniş aile & 26 & 17.9 \\
\hline \multirow{3}{*}{ Ailedeki çocuk sayısı } & $1-2$ & 101 & 69.2 \\
\hline & $3-4$ & 33 & 22.6 \\
\hline & 5 ve üzeri & 11 & 7.5 \\
\hline \multirow{3}{*}{ Ailenin gelir durumu } & Gelir giderden az & 69 & 47.6 \\
\hline & Gelir gidere denk & 61 & 42.1 \\
\hline & Gelir giderden fazla & 15 & 10.3 \\
\hline
\end{tabular}

Bebeklerde ilk çıkan dişinin \%49.0 oranında sağ alt ön kesici dişin olduğu, bunu \%32.4 oranı ile sol alt ön kesici dişin takip ettiği bulundu. Bebeklerin ek gidaya başlama zaman ortalamalarının $6.55 \pm 2.33$ ay olduğu ve \%89.7'sinin D vitamini kullandığı tespit edildi. Annelerin \%62.8'inin diş çıkarma süreci ile ilgili bilgi almadığı ve \%39.3'ünün bebeği için diş kutlaması yaptığg belirlendi (Tablo 2). 
Tablo 2. Diş Çıkarma Süreci ile İlgili Özelliklerin Dağılımı $(N=145)$

\begin{tabular}{llll}
\hline Özellikler & & $\mathbf{n}$ & \% \\
\hline İlk çıkan diş & Alt ön kesici dişi (să̆) & 71 & 49.0 \\
& Alt ön kesici dişi (sol) & 47 & 32.4 \\
& Üst ön kesici dişi (sağ) & 23 & 2.8 \\
& Üst ön kesici dişi (sol) & 4 & 37.2 \\
\hline $\begin{array}{l}\text { Diş çıarma süreci ile ilgili bilgi } \\
\text { alma }\end{array}$ & Evet & 54 & 62.8 \\
\hline D vitamini kullanma & Hayır & 91 & 89.7 \\
& Evet & 130 & 10.3 \\
\hline Diş kutlaması yapma & Hayır & 15 & 39.3 \\
\end{tabular}

\begin{tabular}{lc}
\hline & Ortalama \pm SS \\
\hline Ek gıdaya başlama zamanı (ay) & $6.55 \pm 2.33$ \\
\hline
\end{tabular}

Bebeklerin ilk dişlerini 4-18 ay arasında çıkardığ bulundu. Araştırmamızda erkeklerde diş çıkarma zamanının (7.34 \pm 2.11$)$ kızlarda diş çıkarma zamanına (7.76 \pm 2.3$)$ göre daha erken olduğu ancak aralarındaki farkın istatistiksel olarak anlamlı olmadığ saptand 1 ( $\mathrm{p}=0.410)$. Araştırmamıza katılan bebeklerin \%95.9'unun ( $\mathrm{n}=139)$ diş çıkarma sürecinde en az bir sorun yaşadı̆̆ 1 bulunmuş olup, yaşanan sorunlar Tablo 3'te verildi. Bebeklerin diş çıkarma sürecinde en fazla yaşadıkları sorunların; huzursuzluk (\%76.6), diş etlerinde kızarıklık, kaşıntı (\%64.8), 1sırma ve çiğnemede artış (\%55.2), salyada artış (\%52.4), uykusuzluk (\%49.7), ateş (\%48.3), iştahta azalma (\%35.2), kulakta kaşıntı, kulağı ovma veya çekme (\%29.0), ishal (\%28.3), pişik (\%28.3) ve emme isteğinde artış (\%27.6) olduğu saptandı (Tablo 3).

Tablo 3. Bebeklerin Diş Çıkarma Sürecinde Yaşadıkları Sorunların Dağılımı (N=145)

\begin{tabular}{lcc}
\hline Sorunlar* & $\mathbf{n}$ & \% \\
\hline Huzursuzluk & 111 & 76.6 \\
Diş etlerinde kızarıklık, kaşıntı & 94 & 64.8 \\
Isırma ve çiğnemede artış & 80 & 55.2 \\
Salyada artış & 76 & 52.4 \\
Uykusuzluk & 72 & 49.7 \\
Ateş & 70 & 48.3 \\
İştahta azalma & 51 & 35.2 \\
Kulakta kaşıntı, kulağı̀ ovma veya çekme & 42 & 29.0 \\
Pişik & 41 & 28.3 \\
İshal & 41 & 28.3 \\
Emme isteğinde artış & 40 & 27.6 \\
Burun tıkanıklı̆̆ı & 22 & 15.2 \\
Bez bölgesinde kızarıklık & 20 & 13.8 \\
Konstipasyon & 17 & 11.7 \\
Burun akıntısı & 15 & 10.3 \\
Öksürük & 11 & 7.6 \\
Kusma & 9 & 6.2 \\
\hline
\end{tabular}

*Birden çok yanıt verilmiştir.

Annelerin diş çıkarma sürecinde bebeklerinin yaşadıkları sorunlara yönelik en fazla yaptıkları uygulamaların; çiğnemesi için yiyecek verme (\%71.0), diş kaşıma halkası verme (\%60.0), diş jeli sürme (\%43.4), hekimin önerdiği ağrı kesici ilaç verme (\%35.9), diş etine masaj yapma (\%34.5), emzirme sıklığını artırma (\%30.3) ve emzik verme (\%28.3) olduğu belirlendi (Tablo 4). Araştırmaya katılan annelerin \%47,6'sı $(n=69)$ yaptıkları bu uygulamaların bebeklerinin yaşadıkları sorunları azalttığını ifade etti. 
Tablo 4. Annelerin Diş Çıkarma Sürecinde Bebeklerinin Yaşadıkları Sorunlara Yönelik Uygulamalarının Dağılımı (N= 145)

\begin{tabular}{lcc}
\hline Uygulamalar* & $\mathbf{n}$ & $\mathbf{\%}$ \\
\hline Çiğnemesi için yiyecek (havuç, pırasa, yeşil soğan vb.) verdim. & 103 & 71.0 \\
Diş kaşıma halkası verdim. & 87 & 60.0 \\
Diş jeli sürdüm. & 63 & 43.4 \\
Hekimin önerdiği ağrı kesici ilaç verdim. & 52 & 35.9 \\
Diş etine masaj yaptım. & 50 & 34.5 \\
Emzirme sıklığını artırdım. & 44 & 30.3 \\
Emzik verdim. & 41 & 28.3 \\
Kehribar taşlı kolye, bileklik taktım. & 21 & 14.5 \\
Doğal bitkisel ürün verdim. & 12 & 8.3 \\
Hekimin önerdiği antibiyotik verdim. & 7 & 4.8 \\
\hline
\end{tabular}

*Birden çok yanıt verilmiştir.

\section{Tartışma}

Bebeklerin süt dişleri genellikle doğumdan 4-10 ay sonra çıkmaya başlar (16). Araştırmamızda bebeklerin ilk dişlerini 4-18 ay arasında çıkardığı, bebeklerin ortalama diş çıkarma zamanının $7.55 \pm 2.24$ ay olduğu bulundu. Kılınç ve ark. (2015) tarafindan yapılan çalışmada bebeklerin süt dişi çıkarma zamanının 3 ay-13 ay arasında değişmekte olup, ortalamasının $7.7 \pm 2.0$ ay olduğu bulunmuştur (3). Baykan ve ark.'1 (2004) ilk süt dişini çıkarma zamanını $7.4 \pm 2.0$ ay; Un Lam ve ark.'1 (2016) $8.5 \pm 2.6$ ay; Plutzer ve ark.'1 (2012) $7.1 \pm 2.3$ ay; Mohammed ve ark.'1 (2012) $7.5 \pm 2.0$ ay; Kariya ve ark.'1 (2018) $8.15 \pm 1.69$ ay olarak bulmuşlardır $(2,5,9,13,17)$. Prenatal, perinatal, postnatal dönemlerdeki birçok endojen ve eksojen faktörler diş çıkarma zamanını etkilemektedir (7). Literatürde her ne kadar diş çıkarma zamanı bazı faktörlere göre değiş̧iklik gösterse de yapılan çalışmalarda bebeklerin ilk dişini çıkarma zamanı benzer bulunmuştur.

Araştırmamızda erkeklerde $(7.34 \pm 2.11)$ diş çıkarma zamanının kızlara $(7.76 \pm 2.3)$ göre daha erken olduğu ancak aralarındaki farkın istatistiksel olarak anlamlı olmadığ $\operatorname{saptand}_{1}(\mathrm{p}=.410)$. Araştırmamıza benzer şekilde Baykan ve ark.' $1(2004)$ bebeklerin cinsiyetine göre diş çıkarma zamanının değişmediğini bulmuştur (2). Diğer taraftan bazı çalışmalarda $(3,17,18)$ erkek çocuklarda kız çocuklarına göre dişlerin daha erken çıktığı ve farkın istatistiksel olarak anlamlı olduğu bulunmuştur. Çalışmalardaki sonuçların benzer olmaması çalışmaların farklı ülkelerde ve farklı örneklem gruplarında yapılmış olmasından kaynaklanabilir.

Araştırmamızda bebeklerin ilk çıkan dişinin daha yüksek oranda alt ön kesici dişlerin (sağ=\%49.0; sol=\%32.4) olduğu bulunmuştur. Baykan ve ark.'1 (2004) çalışmalarında ilk çıkan dişin \%86 oranında alt ön kesici dişler olduğunu saptamıştır (2). Ülkemizde yapılan başka bir çalışmada da bebeklerin ilk çıkan dişlerinin alt ön kesici dişler (sağ $=\% 60.5$; sol=\%26.1) olduğu belirlenmiştir (3). Kariya ve ark.'1 (2018) çalışmalarına katılan bebeklerin alt ön kesici dişlerinin daha erken (8.30 \pm 1.06 ay) çıktığını saptamıştır (17). Araştırma sonucumuz literatür $(2,3,17)$ ile benzerlik göstermektedir.

Ebeveynler diş çıarmayı çocuğun büyümesinde ve gelişmesinde önemli bir olay olarak görmektedir (19). Bu önemli olay ülkemizin çeşitli bölgelerinde 'diş bulguru, diş buğdayı, diş hediği, diş aşı' gibi çeşitli isimler ile kutlanmaktadır. Bu kutlamanın temel amacı bebeğin gelişim evrelerinden birini gerçekleştirdiğini duyurmak, bu sevinci akraba ve dostlarla paylaşmaktır (20). Bu doğrultuda araştırmaya katılan annelerin \%39.3'ünün bebeği için diş kutlaması yapmasının, toplumsal olarak diş çıkarmaya yüklenen anlamlar ile ilişkili olduğu düşünüldü.

Diş çıkarma, süt dişlerinin belirli sırayla diş etini yararak ağız boşluğunda belirdiği doğal ve fizyolojik bir süreçtir (5). Diş çıkarma, bebeğin gelişiminin normal bir parçası olmasına rağmen bu sürece birçok lokal ve sistemik semptom eşlik etmektedir (7). Araştırmamıza katılan annelerin çoğunluğu (\%95.9) bebeklerinin diş çıkarma sürecinde en az bir sorun yaşadığını belirtmişlerdir. Ülkemizde yapılan iki çalışmada bu oran benzer şekilde $\% 98.8$ olarak bulunmuştur $(2,3)$. Memarpour ve ark.'1 (2015) tarafından yapılan çalışmada bebeklerin neredeyse tamamında (\%99.2) diş çıkarma sırasında en az bir semptom yaşandığı tespit edilmiştir (21). Brezilya'da yapılan bir çalışmada bebeklerin \%91.9'unda diş çıkarma sırasında en az bir semptom görüldüğü belirtilmiştir (22). Etiyopya'da yapılan bir çalışmada annelerin \%91.6'sı diş çıkarma sırasında bebeklerinin çeşitli semptomları olduğunu belirtmiştir (23). Geniş örneklemli bir çalışmada ise diş çıkarma semptomlarının çocukların \%80.9'unu etkilediği saptanmıştır (24). Bir çalışmada diş çıkarma sürecinde olan 126 bebeğin \%79.9'unda en az bir semptom olduğu bulunmuştur (25). Feldens ve ark.'1 (2010) tarafindan yapılan çalışmada ise diş çıkarma sırasında bebeklerin sorun yaşama oranı \%73 bulunmuş olup (26), araştırmamıza ve diğer araştırmalara göre daha düşük bulunmuştur.

Amerikan Pediatrik Diş Hekimliği Akademisi (AAPD) diş çıarma sırasında diş etinde hassasiyet, huzursuzluk ve salyada artışın görülebileceğini belirtmektedir (27). Araştırmamızda da bebeklerde diş çıkarma sırasında ilk sıralarda huzursuzluk (\%76.6), diş etlerinde kızarıklık, kaşıntı (\%64.8) ve salyada artış (\%52.4) görülmekle birlikte; 1sırma ve çiğnemede artış, uykusuzluk, ateş, iştahta azalma ve ishal gibi lokal veya sistemik birçok sorun olduğu belirlenmiştir. Literatürde bebeklerin benzer sorunlar yaşadığını gösteren çalışmalar vardır (1-3, 9, 11-13, 15, 21-26, 28, 29). Diş çıkarma fizyolojik bir süreç olmasına rağmen, diş çıkarma ile çocukta semptomların başlaması arasındaki ilişki tartışmalıdır. Bazı araştırmacılar, lokal ve sistemik bulgular ile diş çıkarma arasında bir ilişki olduğuna inanırken, diğerleri diş çıkarmayı herhangi bir sorunla ilişkili olmaksızın fizyolojik bir süreç olarak kabul eder $(19,24)$. Literatürde diş çıkarma sırasında bebeklerin sorun yaşaması ile ilgili kesin bir görüş olmasa da araştırmamızda ve araştırmamıza benzer diğer çalışmalarda (1-3, 9, 11-13, 15, 21-26, 28, 29), anneler 
bebeklerinin diş çıkarma sürecinde lokal veya sistemik birçok sorun yaşadığını belirtmişlerdir.

Bebeklerin diş çıkarma süreci ebeveynler için stresli ve zor geçen bir dönem olabilir (16). Bu nedenle ebeveynler diş çıkarma sürecinde bebeklerini rahatlatmak için çeşitli yöntemlere başvurmaktadır (4). AAPD diş çıkarma sırasında bebeklerin yaşadıkları sorunları yönetmek için oral analjezikleri ve soğuk diş kaşıma halkalarını önerirken; güçlü toksisite özellikleri nedeniyle reçetesiz satılan diş jelleri gibi topikal anestezikleri önermemektedir (27). Araştırmamızda annelerin diş çıkarma sürecinde bebeklerinin yaşadıkları sorunlara yönelik en fazla yaptıkları uygulamaların; çiğnemesi için yiyecek verme (\%71.0), diş kaşıma halkası verme (\%60.0), diş jeli sürme (\%43.4), hekimin önerdiği ağrı kesici ilaç verme (\%35.9), diş etine masaj yapma (\%34.5), emzirme sıklığını artırma (\%30.3) ve emzik verme (\%28.3) olduğu belirlenmiştir. Bu yöntemlerden bebeğe çiğnemesi için yiyecek verme oranı yüksek bulunmuş olup, aspirasyon riski açısından bu tür yiyeceklerin ebeveyn gözetiminde verilmesi ebeveyn eğitiminde vurgulanmalıdır. Araştırmamıza benzer şekilde diğer çalışmalarda (1-3, 9-12, 15, 23, 25, 26, 30) anneler tarafından diş çıkarma sürecinde bebeklerinin sorunları ile başa çıkmak için yüksek oranda farmakolojik veya farmakolojik olmayan yöntemler kullanılmıştır. Başka çalışmalarda $(1-3,9,10,12,15,25,26,30)$ olduğu gibi araştırmamızda da AAPD'nin önermediği diş jelinin anneler tarafindan yüksek oranda tercih edilen bir uygulama olduğu bulunmuştur. Araştırmamızda özellikle ülkemizde son dönemde kullanımı yaygınlaşan kehribar taşı kullanım oranı \%14.5 bulunmuştur. Daha önce yapılmış çalışmalarda ebeveynlerin diş çıkarma sorunlarını yönetmek için kehribar taşı kullanımının sorgulanmadığı görülmektedir. Bunun nedeninin son zamanlarda sosyal medyanın da etkisiyle kehribar taşının diş çıkarma ile ilgili bebeklerin şikayetlerini azalttı̆̆ına yönelik düşüncenin ebeveynler arasında popülarite kazanmış olması olabilir. Ancak kehribar taşının bazı bebeklerde çeşitli dermatolojik sorunlara yol açabileceği, kehribar taşlı kolyenin bazı bebeklerde koparak tanelerinin aspirasyonu nedeniyle, bazı bebeklerde de boğazını sıkması nedeniyle boğulmalara sebep olabileceği belirtilmektedir (31). Bu bilgiler ışığında ebeveynler tarafından diş çıkarma sürecinde bebeklerin sorunları ile başa çıkmada bebeklerin sağlı̆̆ına zarar vermeyecek, güvenli yöntemlerin seçilmesi önem kazanmaktadır. Hemşireler tarafından yapılacak bilgilendirmeler ile uygun olmayan yöntemlerin anneler tarafından kullanılması önlenebilir.

Araştırmaya katılan annelerin \%47,6'sı yaptıkları uygulamaların bebeklerinin yaşadıkları sorunları azalttığını ifade etmiştir. Randomize kontrollü bir çalışmada diş çıkarma sırasında bebeklerin yaşadıkları semptomları azaltmak için en etkili yöntemlerin diş kaşıma halkası verme, kucağa alma ve diş etine masaj yapma olduğu bulunmuştur (21). Diş kaşıma halkası, emzik, diş etine masaj gibi uygulamaların diş etindeki duyusal reseptörlere baskı yaparak ağrıyı azalttığı düşünülmektedir (8). $\mathrm{Bu}$ noktada araştırmamızda çiğnemesi için yiyecek verme, diş kaşıma halkası verme, diş etine masaj yapma annelerin en çok tercih ettiği uygulamalar arasında yer alması nedeniyle annelerin neredeyse yarısı kullandıkları yöntemlerin etkili olduğunu belirtmiş olabilir.

\section{Sinırlılıklar}

$\mathrm{Bu}$ araştırmanın sınırlıklarından birisi tek merkezde yapılması nedeniyle örneklem boyutunun küçük olmasıdır. Bu nedenle bulgular bu araştırmanın örneklem sayısı dikkate alınarak yorumlanmalıdır. Diğer taraftan bu araştırma, gelecekte daha büyük örneklem gruplarında yapılacak çalışmalar için bir temel oluşturabilir. Bebeğin diş çıkarma sırasında yaşadığı sorunları yönetmek için anneler tarafından kullanılan yöntemlerin etkinliğinin ayrı ayrı sorgulanmaması çalışmanın diğer bir sınırlılığıdır. $\mathrm{Bu}$ doğrultuda gelecek araştırmalarda her bir yöntemin etkinliğinin ayrı ayrı değerlendirilmesi önerilebilir.

\section{Sonuçların Uygulamada Kullanımı}

Araştırmamıza katılan annelerin tamamına yakını diş çıkarma sürecinde bebeklerinin en az bir sorun yaşadığını belirtmektedir. Stres oluşturan bu süreçte ebeveynler bebeklerinin sorunlarını çözmek için birçok farklı uygulamaya başvurmaktadır. Bu noktada hemşireler tarafından bebeğin sağlı̆̆ına zarar vermeyecek, uygun, güvenli ve AAPD gibi önemli kuruluşların önerdiğgi yöntemlerin seçilmesi konusunda ebeveynlere bilgi verilmelidir. Bu doğrultuda koruyucu sağllk hizmetleri kapsamında ebeveynlere yönelik eğitim programları planlanabilir.

\section{Bilgilendirme}

Yazarların katkı oranı beyanı şu şekildedir: fikir ve kavram ZE, SK; tasarım ZE, SK, FD; denetleme ve danışmanlık SK; veri toplama ve işleme SK, FD; analiz ve yorum ZE, SK; kaynak taraması ZE, SK; makalenin yazımı ZE, SK; eleştirel düşünme ZE, SK. Araştırma ile ilgili herhangi bir projeden ya da firmadan destek alınmamıştır. Araştırmanın bütçesi araştırmacılar tarafından karşılanmıştır. Yazarlar arasında herhangi bir çıkar çatışması yoktur. Ayrıca sorumlu olduğumuz araştırmada herhangi bir firma ile çıkar ilişskisi bulunmamaktadır. Araştırmanın yapılabilmesi için bir üniversitenin Girişimsel Olmayan Araştırmalar Etik Kurulu’ndan izin alınmıştır (30.10.2020 tarihli ve 2020-44-14 sayılı karar). 


\section{Kaynaklar}

1. Elbur AI, Yousif MA, Albarraq AA, Abdallah MA. Parental knowledge and practices on infant teething, Taif, Saudi Arabia. BMC Res Notes 2015;8(699):1-6.

2. Baykan Z, Sahin F, Beyazova U, Özçakar B, Baykan, A. Experience of Turkish parents about their infants' teething. Child Care Health Dev 2004;30(4):331-336.

3. Kılınç G, Edem P, Günay T, Aydın A, Halıcıoğlu O, Sevinç N. Annelerin çocuklarının süt dişlerinin sürmesi ile ilgili şikâyet ve yaklaşımları. Turkiye Klinikleri J Dental Sci 2015;21(2):90-94.

4. Çelen R, Taş Arslan F. Bebeklerde diş çıkarma süreci ve bu süreçte karşılaşılan sorunlara yönelik uygulamalar. Güncel Pediatri 2018;16(2):181-186.

5. Un Lam C, Hsu CS, Yee R, Koh D, Lee YS, Chong MF ve ark. Influence of metabolic-linked early life factor on the eruption timing of the first primary tooth. Clin Oral Investig 2016;20(8):1871-1879.

6. Zaidi I, Thayath MN, Singh S, Sinha A. Preterm birth: a primary etiological factor for delayed oral growth and development. Int J Clin Pediatr Dent 2015;8(3):215-219.

7. Arıkan D, Bekar P. Çocukların diş çıkarma ağrısında yapılan uygulamalar ve hemşirenin rolü. GÜSBD 2020;9(1):44-47.

8. Ispas RS, Mahoney EK, Whyman RA. Teething signs and symptoms: persisting misconceptions among health professionals in New Zealand. N Z Dent J 2013;109(1):2-5.

9. Plutzer K, Spencer AJ, Keirse MJNC. How first-time mothers perceive and deal with teething symptoms: a randomized controlled trial. Child Care Health Dev 2012;38(2):292-299.

10. Uğurlu E, Kalkım A, Sağkal T. 0-1 yaş arası bebeklerde sık karşılaşılan ağrı durumları ve ailelerin yaklaşımları. Fırat Tıp Dergisi 2014;19(1):25-30.

11. Adam VY, Abhulimhen-Iyoha BI. Teething: beliefs and behaviors of mothers attending well baby clinics in Benin City, Nigeria. Afr J Med Health Sci 2015;14(1):8-12.

12. Hadadi MH. Parental knowledge and practices on infant teething. International Journal of Medicine in Developing Countries, 2019;3(6):521-525.

13. Noor-Mohammed R, Basha S. Teething disturbances; prevalence of objective manifestations in children under age 4 months to 36 months. Med Oral Patol Oral Cir Bucal 2012;17(3):e491-494.

14. Bankole O.O, Lawal F.B. Teething: misconceptions and unhealthy practices among residents of a rural community in Nigeria. Int Q Community Health Educ 2017;37(2):99-106.

15. Owais AI, Zawaideh F, Bataineh O. Challenging parents' myths regarding their children’s teething. Int J Dent Hyg 2010;8(1):28-34.

16. Haznedaroğlu E, Mentes A. The internet versus pediatricians as a source of infant teething information for parents in Turkey. Clinics 2016;71(8):430-434.

17. Kariya P, Tandon S, Singh S, Tewari N. Polymorphism in emergence of deciduous dentition: a cross-sectional study of Indian children. J Invest Clin Dent 2018;9(1):1-5.

18. Choi NK, Yang KH. A study on the eruption timing of primary teeth in Korean children. ASDC J Dent Child 2001;68(4):244-249.

19. Prado AMC, Oliveira FS, de Melo Abrão L, de Paiva Novaes MS, Basso Prado TT. Perception of parents of children with and without disabilities about teething disturbances and practices adopted. Braz J Oral Sci 2013;12(2):76-79.

20. Altaş B. Kutlama ve armağanlarca kuşatılan annelik: diş buğdayı, baby shower ve annelik eksenindeki diğer ritüeller. Mediterranean Journal of Humanities 2018;VIII(2):1-31.

21. Memarpour M, Soltanimehr E, Eskandarian T. Signs and symptoms associated with primary tooth eruption: a clinical trial of nonpharmacological remedies. BMC Oral Health 2015;15(88):1-8.

22. Azevedo MS, Portela AR, Romano AR, Cenci MS. Prevalence of teething symptoms in primary teeth and associated factors: cross sectional study in children aged 12-23 months in Pelotas, Brazil. Br Res Pediatr Dent Integr Clinic 2015;15(1):217225.

23. Getaneh A, Derseh F, Abreha M, Yirtaw T. Misconceptions and traditional practices towards infant teething symptoms among mothers in Southwest Ethiopia. BMC Oral Health 2018;18(1):159.

24. Ferreira FV, Machado MVS, Ardenghi TM, Praetzel JR. Systemic and/or localized manifestations associated with primary tooth eruption: a retrospective study. Pesq Bras Odontoped Clin Integr 2009;9(2):235-239.

25. Olczak-Kowalczyk D, Turska-Szybka A, Gozdowski D, Boguszewska-Gutenbaum H, Krasuska-Sławińska E, Sobiech P ve ark. Longitudinal study of symptoms associated with teething: Prevalence and mothers' practices. Pediatria Polska 2016;91(6):533-540.

26. Feldens CA, Faraco IM, Ottoni AB, Feldens EG, Vítolo MR. Teething symptoms in the first year of life and associated factors: a cohort study. J Clin Pediatr Dent 2010;34(3):201-206.

27. American Academy of Pediatric Dentistry. Perinatal and infant oral health care. The Reference Manual of Pediatric Dentistry. 2020:252-256.

28. Aliyu I, Adewale A, Teslim LO. Teething myths among nursing mothers in North-Western Nigeria. Medical Journal of Dr. D.Y. Patil University 2015;8(2):144-8.

29. Ige OO, Olubukola PB. Teething myths among nursing mothers in a Nigerian community. Niger J Med 2013;54(2):107110.

30. El-Gilany AH, Abusaad FES. Mothers' teething beliefs and treatment practices in Mansoura, Egypt. Saudi Dent J 2017;29(4):144-148. 
31. Güçyetmez Topal B, Falay SB. Hekimler diş sürme dönemi semptomları için kehribar takı kullanımını tavsiye ediyor mu?. Güncel Pediatri 2020;18(1):63-73. 